\title{
Service provision for women undergoing termination of pregnancy: progress in Wales, UK
}

\author{
Allyson Lipp
}

\begin{abstract}
Background This audit established a recent picture of termination of pregnancy services in Wales, UK using the Royal College of Obstetricians and Gynaecologists' Guidelines as a baseline. The context of abortion is rapidly changing and services need to be adaptable to meet women's needs.
\end{abstract}

Methods A questionnaire survey was sent to all National Health Service (NHS) Trusts in Wales; 10 out of 13 responded.

Results In the nine Trusts performing abortions in Wales, medical abortions accounted for $57 \%$ and surgical abortions for $43 \%$. Doctors in training were involved in six Trusts. All but one Trust complied with referral times. Five Trusts provided a dedicated clinic. Written information provided prior to abortion varied in accessibility and quality. Choice of abortion within gestation bands was limited in some Trusts with some only providing medical termination. Essential abortion aftercare was performed by Trusts, whereas follow-up and counselling were less comprehensive.

Discussion Trusts are willing to adapt to new methods of working with an increasing number of medical terminations, although this advantage was offset by a lack of choice of abortion methods offered by some Trusts. Doctors in training should be offered exposure to abortion procedures in all Trusts as this has been shown elsewhere to improve attitudes. Providing dedicated abortion clinics, quality written information and comprehensive abortion aftercare should improve compliance with the guidelines.

Conclusion Overall, in Wales there is compliance with national guidelines, although for a number of the guideline recommendations there remains room for improvement.

Keywords abortion, audit, national guidelines, service provision, termination of pregnancy

J Fam Plann Reprod Health Care 2009; 35(1): 15-19

(Accepted 9 June 2008)

\section{Introduction}

The aim of this audit was to establish current provision in termination of pregnancy (TOP) in National Health Service (NHS) Trusts in Wales, to extract examples of good practice and highlight areas requiring attention before preparing an all-Wales TOP integrated care pathway.

A recent briefing paper by the British Medical Association's Medical Ethics Committee made several suggestions to increase efficiency ${ }^{1}$ supported by a Parliamentary Select Committee. ${ }^{2}$ This included removal of medical criteria for first-trimester abortion, requirement for two doctors' signatures and, controversially, supporting suitably trained nurses/midwives in performing medical (MTOP) and surgical (STOP) termination of pregnancy.

In $2006,90 \%$ of abortions in Wales were NHS-funded and of these $32 \%$ took place in the independent sector in England under NHS contract. ${ }^{3}$ In Wales, $60 \%$ of abortions were performed at less than 10 weeks' gestation. In England and Wales, 30\% of abortions were performed medically, this figure more than doubling in the last 5 years. ${ }^{3}$ The average NHS cost of an abortion is $£ 827$ for STOP and $£ 568$ for MTOP. 4

\section{Methods}

Research governance approval was obtained from 13 NHS Trusts. A questionnaire in English and Welsh based on national guidelines ${ }^{5}$ plus demographic abortion questions was sent to the lead NHS Trust nurse/midwife in Spring

Faculty of Health, Sport and Science, University of Glamorgan, Glyntaf, Pontypridd, UK

Allyson Lipp, MSc, PhD, Principal Lecturer and Research Capacity Building Collaboration (RCBC) Postdoctoral Fellow

Correspondence to: Dr Allyson Lipp, Principal Lecturer and RCBC Postdoctoral Fellow, Faculty of Health, Sport and Science, Room 561, University of Glamorgan, Glyntaf,

Pontypridd CF37 1DL, UK. E-mail: alipp@glam.ac.uk

\section{Key message points}

- Evaluating a service against national guidelines provides data about compliance for each National Health Service (NHS) Trust.

- A national service evaluation provides data for benchmarking against other NHS Trusts.

- The majority of NHS Trusts in Wales are compliant with national guidelines.

2007 regarding 2005 data. Following three reminders, 10 completed questionnaires were returned by September 2007. Two of the three Trusts that did not respond do not provide local NHS abortion services. One major South Wales abortion-providing Trust did not respond.

\section{Results}

\section{Organisation of services in Wales}

NHS abortion services varied greatly between Trusts. One responding Trust was a tertiary centre, whilst some Trusts referred all surgical abortions to non-NHS premises in England under contract (Table 1). ${ }^{6}$ Some 2012 MTOP $(57 \%)$ and 1509 STOP $(43 \%)$ were performed at nine Trusts in Wales in 2005. The total number of STOP $(58 \%)$ and MTOP (42\%) (NHS, NHS Agency and non-NHS) show that overall STOP remain the most common procedure in Wales. ${ }^{7}$

In 6/10 Trusts, doctors in training were involved in TOP tasks including attending the TOP clinic, administering pessaries and dealing with complications. Of the four Trusts that did not involve doctors in training, one Trust is currently developing its service.

\section{Referral}

One Trust did not comply with referral times of 3 weeks due to service constraints ${ }^{5}$ (Table 2) and 5/10 Trusts provided a dedicated assessment clinic as advised for women requesting TOP. 5 
Table 1 Medical (MTOP) and surgical (STOP) terminations of pregnancy performed in National Health Service Trusts in Wales, UK in $2005^{6}$

\begin{tabular}{lccl}
\hline $\begin{array}{l}\text { Trust } \\
\text { number }\end{array}$ & $\begin{array}{l}\text { MTOP } \\
{[\boldsymbol{n}(\%)]}\end{array}$ & $\begin{array}{l}\text { STOP } \\
{[\boldsymbol{n}(\%)]}\end{array}$ & $\begin{array}{l}\text { Choice } \\
\text { MTOP/STOP }\end{array}$ \\
\hline 1 & $113(31)$ & $249(69)$ & Yes \\
2 & $182(28)$ & $477(72)$ & Yes \\
3 & $123(100)$ & 0 & Yes \\
4 & 0 & 0 & - \\
5 & $130(18)$ & $582(82)$ & Yes \\
6 & $246(100)$ & 0 & No \\
7 & $10(100)$ & 0 & No \\
8 & $991(84)$ & $190(16)$ & Yes \\
9 & $217(95)$ & $11(5)$ & Yes \\
10 & $208(42)$ & $290(58)$ & No \\
Total & $2012(57)$ & $1509(43)$ & \\
\hline
\end{tabular}

Table 2 Customary referral times for abortions performed in National Health Service Trusts in Wales, UK in $2005^{6}$

\begin{tabular}{ll}
\hline $\begin{array}{l}\text { Referral time } \\
\text { (days) }\end{array}$ & $\begin{array}{l}\text { Trusts } \\
(\boldsymbol{n})\end{array}$ \\
\hline$>14$ & 4 \\
$15-21$ & 3 \\
$22-28$ & 1 \\
No response & 2 \\
\hline
\end{tabular}

\section{Information for women}

Verbal information should be supported by written impartial, printed material. ${ }^{5}$ Five Trusts included the written information (as requested) given during the initial consultation and on discharge. This varied in both content and presentation. All leaflets outlined risks of complications..$^{5}$

\section{Pre-abortion management}

Some unnecessary tests were performed such as blood cross-matching, whilst HIV and hepatitis B and C were screened in only some Trusts (Table 3). All but one Trust performed either a vaginal or abdominal scan in all cases. Two Trusts performed vaginal scans only.

\section{Abortion procedures}

Contrary to national guidelines, 5 three Trusts provided MTOP only and one Trust referred most TOPs out of Wales. The remaining six Trusts provided a choice of MTOP and STOP (Table 1). No Trusts performed STOP under conscious sedation or local anaesthesia. One Trust is currently implementing a feasibility study regarding the possibility of outpatient MTOP.

\section{Medication}

Misoprostol can be administered by the nurse/midwife or the patient. ${ }^{5}$ Six of eight responders stated misoprostol was always $(n=5)$ or often $(n=1)$ given by the nurse/midwife. In two Trusts it was often $(n=1)$ or always $(n=1)$ administered by the patient.

All Trusts complied with the time interval between mifepristone and prostaglandin for MTOP. 5 One Trust administered gemeprost instead of misoprostol.

\section{Abortion aftercare}

Compliance varied for post-abortion tests and services (Table 4). Immunoglobulin $\mathrm{G}$ was always administered if appropriate and the majority of Trusts administered prophylactic antibiotics and analgesia..$^{5}$ However, routine histological tests were performed by three Trusts, contraceptive supplies were issued sporadically and follow-up appointments and counselling were not offered by all Trusts.

\section{Discussion}

\section{Organisation of services in Wales}

Department of Health statistics show that in Wales $90 \%$ of abortions are provided through NHS (58\%) or NHS agency $(32 \%)$ and $10 \%$ are classified as non-NHS. ${ }^{3}$ These figures are encouraging as they suggest improved access but recent concerns about illegal abortions in the UK should counter complacency regarding access. ${ }^{8}$

TOP services differ markedly throughout Wales, with some Trusts contracting out services (Table 1). Rurality and service provision in parts of Wales reduced accessibility and choice, possibly adding to stress for women at a vulnerable time. Table 1 shows a high proportion of MTOP but it should be noted that NHScontracted abortions (mainly STOP) were not included.

Conscientious objection allows doctors to refuse participation in abortion. ${ }^{9}$ With more doctors choosing to conscientiously object, shortages of staff working in this area have been predicted. ${ }^{10,11}$ Involving doctors in training should help to provide sufficient numbers of trained staff willing to work in the area and has been shown to improve attitudes. ${ }^{12}$

The majority of Trusts performing MTOP provided an ostensibly nurse-led service with doctors writing prescriptions and attending any emergencies as advised by a recent Health Technology Assessment. ${ }^{13}$ In a USA study results of experienced physician assistants performing STOP were comparable to physicians. ${ }^{14}$ This possibility has been debated in the UK recently.1,15 The House of Commons Select Committee also advocates expansion of nurses'/midwives' role. ${ }^{2}$

\section{Referral times and assessment}

Only one Trust did not comply with time from initial referral to TOP according to national guidelines.5 This shows the effort made to streamline services, particularly when some are rural. This compares favourably with international studies where barriers were found regarding access. ${ }^{16-18}$

Table 3 Pre-abortion tests/procedures offered in connection with abortions performed in National Health Service Trusts in Wales, UK in $2005^{6}$

\begin{tabular}{llllll}
\hline Test/procedure offered & $\begin{array}{l}\text { Always } \\
(\boldsymbol{n})\end{array}$ & $\begin{array}{l}\text { Often } \\
(\boldsymbol{n})\end{array}$ & $\begin{array}{l}\text { Sometimes } \\
(\boldsymbol{n})\end{array}$ & $\begin{array}{l}\text { Never } \\
(\boldsymbol{n})\end{array}$ & $\begin{array}{l}\text { No response } \\
(\boldsymbol{n})\end{array}$ \\
\hline Haemoglobin level & 9 & & 1 & & \\
Blood grouping & 9 & & 1 & 3 & 1 \\
Cross-matching & 4 & & 1 & 5 & 2 \\
HIV test & & & 1 (Hep C) & 5 & 4 \\
Hepatitis B and C tests & 1 (Hep B) & 2 & 1 & 4 & 1 \\
Cervical smear test & & 2 & 2 & 1 & 1 \\
Abdominal ultrasound scan & 6 & 3 & 1 & \\
Vaginal ultrasound scan & 4 & & & \\
\hline
\end{tabular}


Table 4 Post-abortion tests/services offered in connection with abortions performed in National Health Service Trusts in Wales, UK in 20056

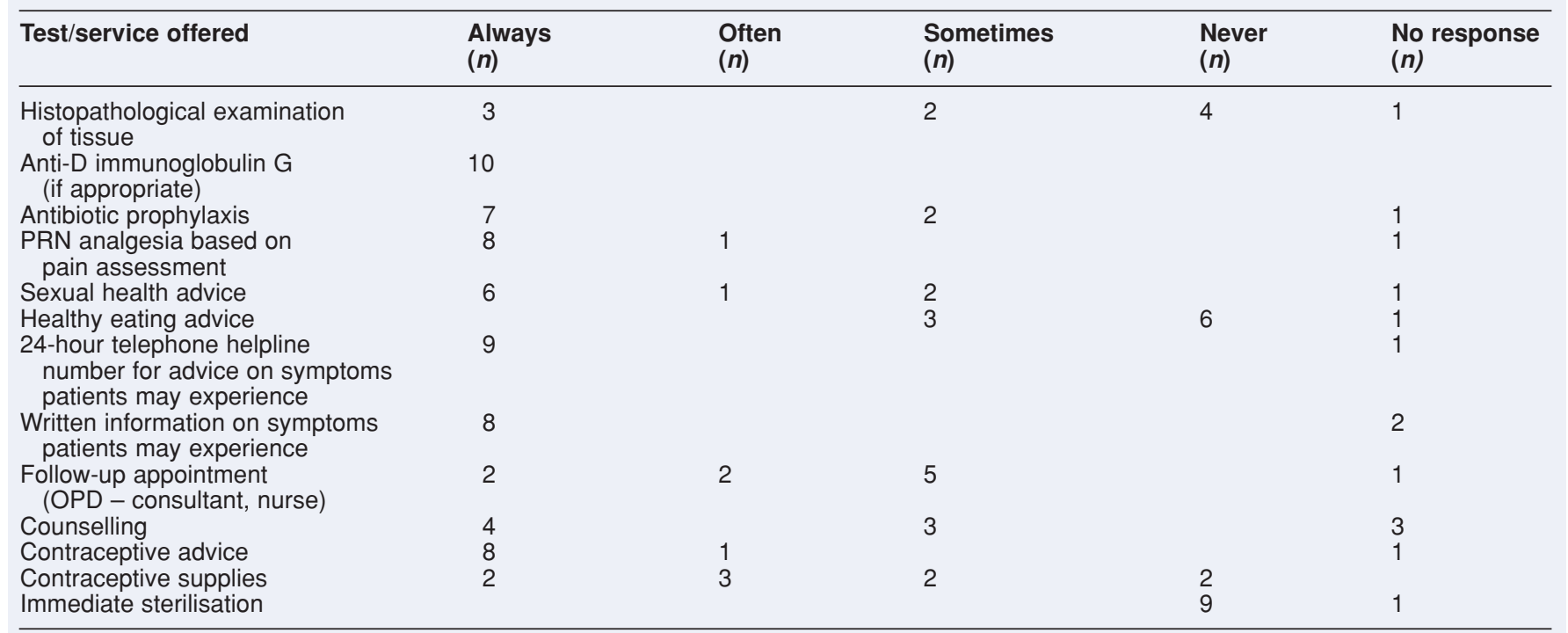

OPD, outpatients department; PRN, pro re nata ('as needed').

Half the Trusts were able to offer dedicated clinics for women at their assessment. ${ }^{5}$ An English study on women's perceptions of TOP care found staff friendliness and being dealt with sensitively important ${ }^{19}$ and a dedicated clinic might achieve this.

\section{Information for women}

Although the majority of Trusts had arrangements for women with special needs such as those changing their mind, or needing more support, no policies were included with the response. Only three Trusts had measures in place for illiterate women to be informed about TOP.

Only half the Trusts included the provision of written information to women. No leaflets referenced national

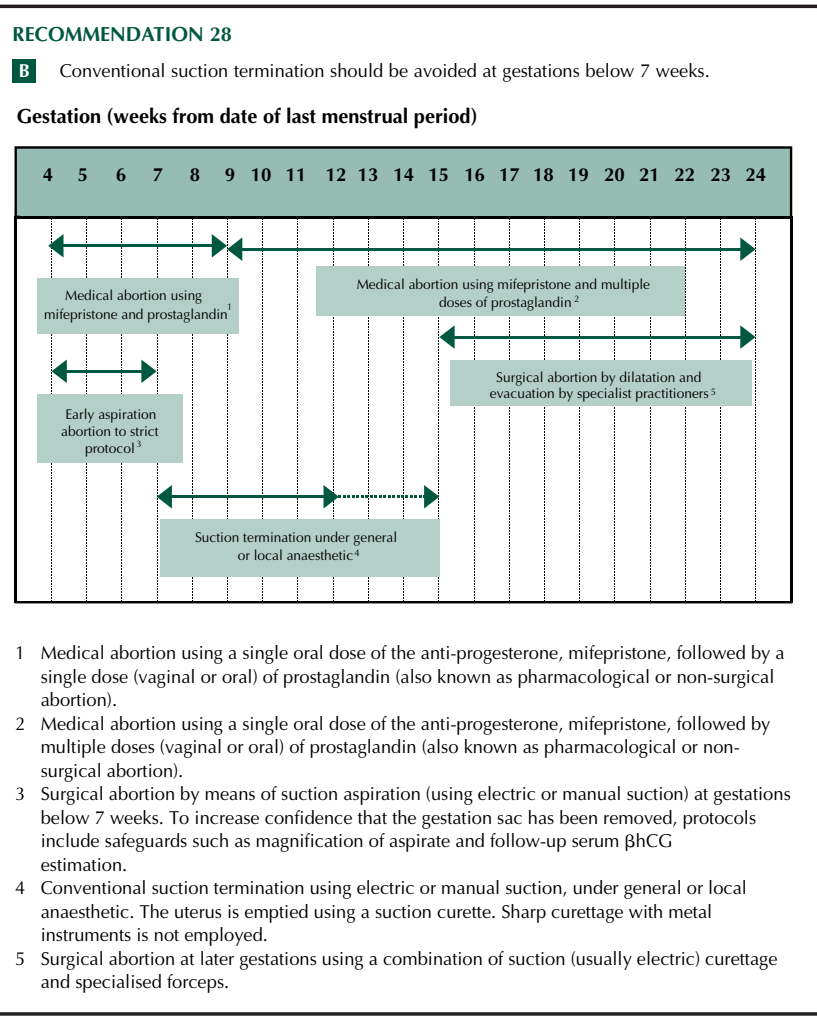

Figure 1 Abortion methods in the UK according to gestation band. ${ }^{5}$ (C) Royal College of Obstetricians and Gynaecologists. Figure reproduced with the kind permission of the copyright holder sources. Information should be impartial and based on that provided by national bodies. ${ }^{5}$ A UK randomised controlled trial (RCT) demonstrated that although there was no difference in TOP method chosen, women provided with the decision aid leaflet had higher knowledge and lower risk perception scores about both. ${ }^{20}$ The authors recommend that an evidence-based decision aid leaflet be provided before initial consultation.

\section{Pre-abortion tests}

Some tests were unnecessarily performed. In a USA study of 7000 MTOP patients only four women required a blood transfusion; extrapolating these results to the UK would negate the need for regular cross-matching. ${ }^{21}$ Some Trusts never performed HIV, hepatitis B and C tests, or cervical smears. A risk-benefit assessment exercise should be done in those Trusts.

Although the majority of Trusts complied with guidelines on antibiotic prophylaxis and chlamydia screening 5 there remains room for improvement (Table 2 ). Chlamydia screening needs to be undertaken sensitively as demonstrated by a systematic review of women's views. 22 Viewing TOP as part of integrated sexual health strategy will help Trusts assimilate TOP into women's sexual health. 23

\section{Abortion procedures}

In six Trusts women were able to choose their method of abortion depending on gestation ${ }^{5}$ (Table 1 and Figure 1). A study by Ho demonstrated that two subsets of women (ie, those that had STOP and those that had MTOP) found TOP to be convenient. ${ }^{24}$ A Danish study found that satisfaction with both methods was high, and was higher when women were given a choice of method. ${ }^{25}$ It is likely that local expertise as well as cost ${ }^{4}$ influences service provision in Wales to a greater extent than women's choice.

Conscious sedation is considered safer than a general anaesthetic. ${ }^{26}$ Guidelines have been available for this procedure since 2002, but it requires a skilled sedationist and no Trusts in this study performed STOP using this or local anaesthetic. Effectiveness of local anaesthetic has been called into question ${ }^{27}$ where high rates of posttraumatic stress disorder were found in STOP patients receiving local anaesthetic. 
One Trust in Wales is currently exploring outpatient MTOP involving careful screening of potential participants. A recent pilot project in the South of England has shown that abortion can be safely performed outside hospital under controlled conditions. ${ }^{28}$ Previously in the UK there has been reluctance by women to undertake selfadministration of medication 29 or consider MTOP at home. ${ }^{30}$ Nevertheless, studies in the USA and Canada have shown that in the right circumstances home MTOP is effective ${ }^{31-33}$ as well as increasing a sense of control in women. ${ }^{34}$ A recommendation to exclude the second stage of early MTOP from the definition of 'carrying out an abortion' will allow further trials to take place. ${ }^{2}$

\section{Medication}

Allowing women to self-administer vaginal misoprostol only occurred in two Trusts. Nevertheless recent research showed it to be $100 \%$ successful with attendant patient satisfaction. ${ }^{29}$ Allowing patient participation would return some control to women and could increase their sense of involvement and responsibility for their health.

All Trusts complied with guidelines regarding the time interval between mifepristone and prostaglandin for MTOP. ${ }^{1}$ A review ${ }^{32}$ based on five RCTs claimed that the interval can be reduced from 48 to 24 hours without loss of efficacy, and further recommends that there is sufficient evidence to reduce this time period to 6-8 hours. However, results of an RCT comparing misoprostol either 6 hours later or 36-48 hours after mifepristone ${ }^{35}$ showed less efficacy at 6 hours. On this basis, reducing the time interval between stages in MTOP could proceed with caution.

A study comparing both gemeprost and misoprostol in first-trimester abortions found them to be equally effective. ${ }^{36}$ Mean cost per patient was US\$1.48 (£0.98) for misoprostol and US\$85.79 (£57.08) for gemeprost. ${ }^{37}$ Based on this evidence, the sole Trust using gemeprost instead of misoprostol would need to justify its continued use..$^{5}$

\section{Abortion aftercare}

Rhesus typing and anti-D immunoglobulin $G$ were performed as per national guidelines 5 although there is little evidence sensitisation could occur under 63 days' gestation. ${ }^{38}$ Although routine histological testing of tissue is deemed unnecessary, in three Trusts where this took place TOPs were mainly undertaken for fetal abnormality.

Antibiotic prophylaxis was only provided sometimes by two Trusts despite it preventing both short- and longterm detrimental effects. ${ }^{5}$ Compliance with analgesia was evident in the majority of Trusts where administration was based on patient need and pain assessment.

In never providing contraceptive supplies, two Trusts missed opportunities to check that women have adequate contraception immediately following TOP. ${ }^{5,38}$ In a USA study most participants were not using contraception at the time of conception. ${ }^{39}$

Post-abortion counselling is recommended as being available for the minority of women who may require $\mathrm{it}^{5}$ and as far as can be ascertained this is the case in Wales. In a recent phenomenological study an attempt was made to gain insights into a complex situation. ${ }^{40}$ However, whether counselling positively influences long-term outcomes is by no means certain. 41

A major limitation of this study was the questionnaire design as the aim was to capture the maximum amount of data whilst keeping the questionnaire simple. Inevitably, the quest for the maximum amount of data overrode simplicity and some of the resultant data were analysed with difficulty. In hindsight, piloting the questionnaire using an English NHS Trust would have minimised these difficulties.

\section{Conclusions}

RCOG guidelines were first introduced in 2000 and have since been updated..$^{5} \mathrm{~A}$ further update is recommended via the National Institute for Health and Clinical Excellence. ${ }^{2}$ The purpose of this study was to examine abortion services in Wales and their adherence to current RCOG guidelines in preparation for development of an integrated pathway of care.

Stricter adherence to guidelines by some Trusts would reap clinical benefits. Opportunity for doctors in training to be exposed to or contribute to TOP care and treatment in each NHS Trust in Wales together with dedicated TOP clinics is commended as evidence-based practice. ${ }^{12,19}$ As a result of this audit, development is currently underway of an all-Wales template for patient information and TOP choice with local adaptation by each Trust, as well as an all-Wales multidisciplinary pathway of care for TOP to encourage compliance with RCOG guidelines and streamline care.

It would be prudent of Trusts to rationalise preabortion testing according to RCOG guidelines to reduce inefficiency. In line with greater patient involvement, there is more scope for misoprostol to be administered by women undergoing abortion. There is opportunity to provide contraception immediately after TOP to reduce risk of a repeat procedure.

In some instances, compliance may have resource implications such as the need to provide a dedicated TOP clinic. However, the extra resources required could be offset against the cost of unnecessary tests and investigations that are performed in some instances.

\section{Acknowledgements}

The author would like to acknowledge the support of the Research Capacity Building Collaboration, Wales, the NHS Trusts in Wales, and the University of Glamorgan for facilitating this service evaluation.

\section{Statements on funding and competing interests}

Funding The author would like to acknowledge the financial support provided by the Research Capacity Building Collaboration, Wales, UK

Competing interests None identified.

\section{References}

1 British Medical Association (BMA). First Trimester Abortion: A Briefing Paper by the BMA's Medical Ethics Committee. London, UK: BMA, 2007; 1-6.

2 House of Commons Science and Technology Committee. Scientific Developments Relating to the Abortion Act 1967. Twelfth Report of Session 2006-07, Volume 1. London, UK: The Stationery Office, 2007; 1-93.

3 Department of Health. Abortion Statistics, England and Wales: 2006. London, UK: Department of Health, 2006.

4 Department of Health. National Schedule of Reference Costs - NHS Trusts. Leeds, UK: Department of Health, 2006.

5 Royal College of Obstetricians and Gynaecologists (RCOG). The Care of Women Requesting Induced Abortion (Evidencebased Clinical Guideline Number 7). 2004. http://www.rcog. org.uk/resources/Public/pdf/induced_abortionfull.pdf [Accessed 4 April 2008].

6 Lipp A. An all-Wales examination of service provision for women undergoing termination of pregnancy: Phase One (Unpublished report). Pontypridd, UK: University of Glamorgan, 2008; 1-26.

7 National Assembly for Wales. Health Statistics Wales 2006. Chapter 9: Abortions. Cardiff, UK: National Assembly for Wales, 2006.

8 Haslam P. Illegal abortions still blight UK. BBC Radio 5 Live report, 26 November 2007.

9 British Medical Association (BMA). The Law and Ethics of Abortion: BMA Views. London, UK: BMA, 1999; 1-10.

10 BBC News. Abortion 'crisis' threatens the NHS, BBC News report, 16th April 2007.

11 Nuttall C. Conscientious objection: justified or just refusal to care? J Perioper Pract 2007; 17: 210-215

12 Shotorbani S, Zimmerman FJ, Bell JF, Ward D, Assefi N. Attitudes and intentions of future health care providers toward abortion provision. Perspect Sex Reprod Health 2004; 36: 58.

13 National Board of Health. Medical Versus Surgical First 
Trimester Abortion. A Health Technology Assessment Summary. Copenhagen, Denmark: Danish Centre for Evaluation and Health Technology Assessment, 2005.

14 Goldman M, Occhiuto J, Peterson L, Zapka J, Palmer H. Physicians assistants as providers of surgically induced abortion services. Am J Public Health 2004; 94: 1352-1357.

15 Argent V, Pavey L. Can nurses legally perform surgicalinduced abortion? J Fam Plann Reprod Health Care 2007; 33 79-82.

16 Henshaw S. Factors hindering access to abortion services. Fam Plann Perspect 1995; 27: 54-87.

17 Moreau C, Bajos N, Bouyer J, Group C. Access to health care for induced abortions. Eur J Public Health 2004; 14: 369-374.

18 Ferris LE, McMain-Klein M, Iron K. Factors influencing the delivery of abortion services in Ontario: a descriptive study. Fam Plann Perspect 1998; 30: 134

19 Slade P, Heke S, Fletcher J, Stewart P. Termination of pregnancy: patients' perceptions of care. J Fam Plann Reprod Health Care 2001; 27: 72-77.

20 Wong SSM, Thornton JG, Gbolade B, Bekker HL. A randomised controlled trial of a decision-aid leaflet to facilitate women's choice between pregnancy termination methods. $\mathrm{Br}$ J Obstet Gynaecol 2006; 113: 688-694.

21 Fielding SL, Lee SS, Schaff EA. Professional considerations for providing Mifepristone-induced abortions. Nurse Pract 2001; 26: 44-48.

22 Pavlin N, Gunn J, Parker R, Fairley C, Hocking J. Implementing chlamydia screening: what do women think? A systematic review of the literature. BMC Public Health 2006; 6 : 221-232.

23 Department of Health. The National Strategy for Sexual Health and HIV. London, UK: Department of Health, 2001.

24 Ho PC. Women's perceptions on medical abortion. Contraception 2006; 74: 11.

25 Rorbye C, Norgaard M, Nilas L. Medical versus surgical abortion: comparing satisfaction and potential confounders in a partly randomized study. Hum Reprod 2005; 20: 834-838.

26 Department of Health. Conscious Sedation in Termination of Pregnancy: Report of the Department of Health Expert Group. London, UK: Department of Health, 2002; 1-11.

27 Suliman S, Ericksen T, Labuschgne P, de Wit R, Stein D, Seedat S. Comparison of pain, cortisol levels, and psychological distress in women undergoing surgical termination of pregnancy under local anaesthesia versus intravenous sedation. BMC Psychiatry 2007; 7: 24

28 BBC News. Study finds home abortion 'safe'. BBC News report, 15 February 2006. http://news.bbc.co.uk/1/hi/ health/4717786.stm [Accessed 14 March 2008].

29 Kiran U, Amin P, Penketh R. Self-administration of vaginal misoprostol after mifepristone for termination of pregnancy: patient acceptability. Int J Gynecol Obstet 2006; 26: 679-681.

30 Hamoda H, Critchley H, Paterson K, Guthrie K, Roger M, Penney G. The acceptability of home medical abortion to women in the UK setting. Br J Obstet Gynaecol 2005; 112: 781-785.

31 Shannon C, Wiebe E, Jacot F, Guilbert E, Dunn S, Sheldon W, et al. Regimens of misoprostol with mifepristone for early medical abortion: a randomised trial. $\mathrm{Br} J$ Obstet Gynaecol 2006; 113: 621-628.

32 Schaff E. Evidence for shortening the time interval of prostaglandin after mifepristone for medical abortion. Contraception 2006; 74: 42

33 Schaff E, Fielding S, Eisinger S. Low-dose mifepristone followed by vaginal misoprostol at 48 hours for abortion up to 63 days. Contraception 2000; 61: 41-46.

34 Fielding SL, Edmunds E, Schaff EA. Having an abortion using mifepristone and home misoprostol: a qualitative analysis of women's experiences. Perspect Sex Reprod Health 2002; 34: 34.

35 Guest J, Chien P, Thompson M, Kosseim M. Randomised controlled trial comparing the efficacy of same-day administration of mifepristone and misoprostol for termination of pregnancy with the standard 36 to 48 hour protocol. $\mathrm{Br} J$ Obstet Gynaecol 2007; 114: 207-215.

36 Svendsen PF, Rorbye C, Vejborg T, Nilas L. Comparison of gemeprost and vaginal misoprostol in first trimester mifepristone-induced abortion. Contraception 2005; 72: 28.

37 Azlin MN, Abdullah H, Rashid MZ, Jamil M. Misoprostol (alone) in second trimester terminations of pregnancy: as effective as gemeprost? Int J Gynecol Obstet 2006; 26: 546-549.

38 von Hertzen H, Baird D. Frequently asked questions about medical abortion. Contraception 2006; 74: 3

39 Goss GL. The perception of pain and knowledge-seeking in women choosing medical abortion. Clin Excell Nurse Pract 2004; 8: 172.

40 Trybulski J. The long-term phenomena of women's postabortion experiences. West J Nurs Res 2005; 27 559-576.

41 Fergusson D. Abortion in young women and subsequent mental health. J Child Psychol Psychiatry 2006; 47: 16-24.

FICTION BOOK REVIEW

The Outcast. Sadie Jones. London, UK: Vintage Books, 2008. ISBN-13: 978-0-099-51342-1 Price: £7.99. Pages: 444 (paperback)

Don't be put off by the cover, which makes it look like a romantic novel, or by the "Richard \& Judy Summer Read" recommendation. This is no superficial poolside novel, but one that explores unhappiness and suffering, as well as emotional and physical abuse.

The book opens with 19-year-old Lewis as he leaves Brixton prison, buys some new clothes with a postal order from his father and travels to meet a chilly reception at his father's house in rural Surrey. The novel then goes back to 1945, when 7-year-old Lewis and his mother. Elizabeth, greet his father, Gilbert, who has just returned from the war. Cold and remote, Gilbert stifles any display of emotion, curiosity or playfulness in his son and wife. Gilbert goes back to his job, accepting humiliation uncomplainingly from his bullying boss, Mr Carmichael. The author describes well the yearning felt by Elizabeth for emotion and gaiety, her despair blotted out by recourse to alcohol. Elizabeth concentrates her love and attention on her young son. It would, perhaps, have made the book too unwieldy to look also at the reasons for the emotional coldness exhibited by Gilbert - perhaps damaged by his experiences in the war? The autho portrays his behaviour as normal in this middleclass environment of the stiff upper lip.

Taking a swim after a riverside picnic Elizabeth drowns, and Lewis is the sole witness. At the inquest, Lewis just stutters when asked to testify. To Gilbert, Lewis's mouth becomes "a kind of wound", and he continues the pattern of repression. Gilbert seeks solace with a new wife, a selfish young woman who cannot cope with Lewis's grief. In fact, Lewis's unbearable grief is ignored by everyone as unacceptable, and he's left utterly bereft and alone. The enormous pressure on him to conform socially is too much, and he finds solace in hidden drinking and selfharm. The author's description of Lewis' feelings of elation after cutting himself and the relief it brings show real insight into self-harming behaviour. Misunderstood by his father an goaded by his father's boss, Mr Carmichael, Lewis's behaviour becomes increasingly erratic until, in desperation, he turns to arson and is sent to prison.

When he returns, only one person seems to (almost) understand him: Kit, the younge daughter of $\mathrm{Mr}$ Carmichael and also an outsider. From an early age, she has idolised Lewis, so when he begins to self-destruct she blames others instead of the victim. The bullying $\mathrm{Mr}$ Carmichael turns from physically abusing his wife to beating Kit and the author describes well how Kit feels trapped into accepting his beatings. Kit's manipulative attractive sister toys with Lewis for the thrill of it, while her mother maintains a frigid air of disapproval. Lewis recognises the dysfunctions in the relationships of those around him and the way in which no one speaks of them. When he speaks out, the fury of those exposed is great.

The author evokes a small world of rigid social constraints. It's a world where, on the outside, everything looks conventional and safe. Look deeper and you find alcoholism, child abuse and domestic violence that destroy people's lives. Lewis is terribly damaged, but we can understand his violence and fury. As health professionals we can recognise and learn from the descriptions of the reactions to emotional and physical abuse occurring unseen by the outside world, compounded by the tight social hierarchy and constraints of the stifling 1950s environment.

Reviewed by Gill Wakley, MD, FFSRH Advisory Editor Journal of Family Planning and Reproductive Health Care

We hope that journal readers enjoyed reading The Outcast, and also discovering whether their opinion of the book matched that of our guest reviewer. In the April 2009 issue, the fiction book under scrutiny will be The Memory Keeper's Daughter by Kim Edwards (416 pages, Penguin Books, 2007, ISBN-13: 9780-14103-014-2). We want to remind journal readers that if they would like to offer to review an appropriate fiction title of their own choosing then they should contact the Journal Editorial Office by e-mail (journal@fsrh.org) in the first instance with details of their nominated title. 